Volume 1 - Número 14 - Primeiro Semestre de 2013

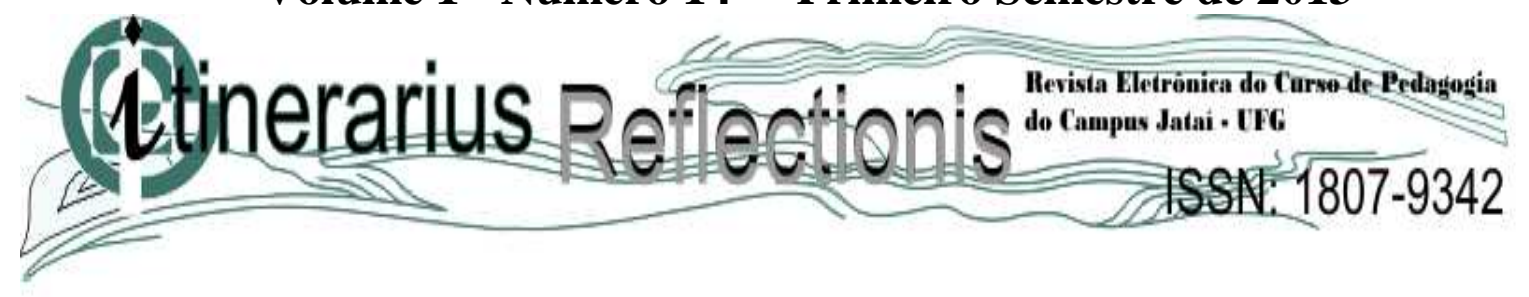

\title{
MATERIAL CONCRETO: UMA ESTRATÉGIA PEDAGÓGICA PARA TRABALHAR CONCEITOS MATEMÁTICOS NAS SÉRIES INICIAIS DO ENSINO FUNDAMENTAL
}

\author{
Anderson Oramisio Santos ${ }^{1}$ \\ Universidade Federal de Uberlândia \\ oramisio@hotmail.com \\ Camila Rezende Oliveira ${ }^{2}$ \\ Universidade Federal de Uberlândia \\ milarezendeoliveira@gmail.com \\ Guilherme Saramago de Oliveira ${ }^{3}$ \\ Universidade Federal de Uberlândia \\ gsoliveira@ufu.br
}

\begin{abstract}
RESUMO O presente trabalho traz reflexões sobre a importância da correta utilização do material concreto para o ensino de matemática nas séries iniciais do Ensino Fundamental, buscando algumas contribuições para o professor quanto a sua aplicabilidade, de forma que ocorra uma aprendizagem significativa dos conceitos matemáticos em sala de aula. O material concreto desenvolve o raciocínio do aluno estimulando o pensamento lógico matemático, na construção de esquemas conceituais dando contornos e significados. È por meio dessas interações com o meio físico e social, que a criança constrói seu conhecimento. Trata-se de uma pesquisa bibliográfica, apoiada em teóricos embrenhados na temática tais como FREIRE, D'AMBRÓSIO, PAIS, MICOTTI, e outros, documentos oficiais do governo como os Parâmetros Curriculares Nacionais (PCNs, 1998), com a finalidade de investigar e compreender de que forma o uso dos materiais concretos manipuláveis, podem intervir no processo de ensino aprendizagem da matemática, tendo em vista que estes proporcionam aos alunos maior interesse e cuidados por parte do professor durante a utilização destes. Constatou-se que os materiais concretos devem servir como mediadores para facilitar a relação professor/aluno/conhecimento no momento em que um saber está sendo construído e que as relações matemáticas não estão no objeto em si, elas podem formar na cabeça da criança, cujos conhecimentos matemáticos transformam-se em componentes significativos de conhecimento do mundo real, desde que o material seja bem utilizado e instrumentalizado pelo professor. Espera-se também que essas reflexões contribuam para o processo de formação continuada dos professores, na intenção de potencializar discussões e vivências que possibilitem novas práticas pedagógicas em sala de aula visando qualificar o ensino de matemática e organizar situações que provoquem a curiosidade e busca de soluções, possibilitando utilizar o
\end{abstract}

1 Graduado em Pedagogia, Especialista em Psicopedagogia e Mestrando em Educação pela Universidade Federal de Uberlândia. Professor da rede pública estadual.

2 Graduada em Pedagogia, Especialista em Supervisão Escolar e Mestranda em Educação pela Universidade Federal de Uberlândia. Professora da rede pública municipal

3 Doutor em Educação na Universidade Federal de Uberlândia. Professor Titular na Universidade Federal de Uberlândia. Docente do Curso de Pedagogia e do Programa de Pós Graduação em Educação da Universidade Federal de Uberlândia 


\section{Volume 1 - Número 14 - Primeiro Semestre de 2013}

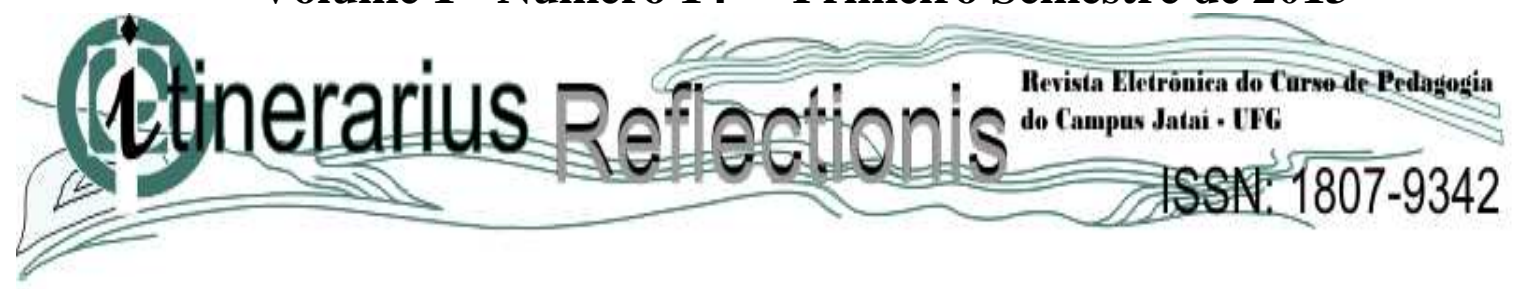

conhecimento científico em situações do cotidiano. Faz-se neste um breve levantamento de alguns aspectos que nortearão a discussão no desenvolvimento do texto.

PALAVRAS - CHAVE: Matemática, Ensino-aprendizagem, Material Concreto.

ABSTRACT This paper reflects on the importance of the correct use of concrete materials for teaching mathematics in the early grades of elementary school, seeking some contributions to the teacher as to its applicability so that meaningful learning occurs mathematical concepts in room class. The concrete material develops the student's reasoning stimulating logical thinking mathematician, in the construction of conceptual schemes giving contours and meanings. It is through these interactions with the physical and social environment, the child builds his knowledge. It is a literature search, based on theoretical caught up in the theme such as Freire, D'AMBRÓSIO, PARENTS, Micotti, and other official government documents such as the National Curriculum Parameters (PCN 1998), in order to investigate and understand how the use of concrete materials, manipulatives, may intervene in the process of teaching and learning of mathematics, in order that they provide students with greater interest and care by the teacher while using these. It was found that the concrete materials should serve as mediators to facilitate the teacher / student relationship / knowledge at the time that a knowledge is being constructed and mathematical relationships that are not in the object itself, they can form the head of the child, whose mathematical transform into significant components of real-world knowledge, since the material is well used and exploited by the teacher. It is also hoped that these reflections contribute to the process of continuous training of teachers, in an attempt to enhance discussions and experiences that enable new pedagogical practices in the classroom in order to qualify the math and organize situations that provoke curiosity and search for solutions enabling use scientific knowledge in everyday situations. This makes up a brief survey of some aspects that will guide the discussion on the development of the text

Keywords: Mathematics Teaching-Learning Material Concrete

\section{INTRODUÇÃO}




\section{Volume 1 - Número 14 - Primeiro Semestre de 2013}

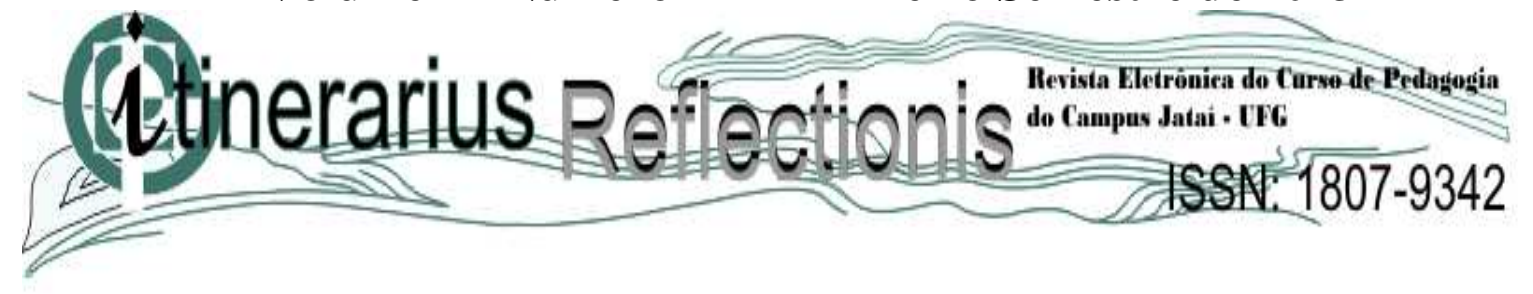

A Matemática, na maioria das vezes, é vista como uma disciplina pronta e acabada, sem espaço para a criatividade. Isso acaba gerando uma grande aversão nos alunos, fazendo com que acreditem que é algo difícil, distante da realidade e, muitas vezes, sem utilidades, onde quem aprende ou a compreende é considerado muito inteligente. O que devemos fazer é tirar a ideia de que a matemática é para poucos e, mostrar que todas as pessoas têm a capacidade de aprendê-la e ainda explorar o lúdico.

A matemática está entre as principais matérias para a formação do aluno e da sociedade, pois estabelece uma relação entre o cotidiano e a vida social, no entanto, é fundamental que os alunos tenham contato com a matéria a partir das séries iniciais.

A aprendizagem da matemática contribui para o desenvolvimento do raciocínio, da lógica e da coerência, que são os aspectos práticos. $\mathrm{O}$ ensino da matemática exige do educador muita dedicação e a visão geral do processo de ensino aprendizagem.

Os diferentes campos da matemática devem interagir, de forma articulada, com as atividades que serão desenvolvidas pelos alunos no ensino fundamental, não apenas as questões algébricas, mas são também de suma importância os trabalhos geométricos e os que envolvem o raciocínio combinatório e probabilístico e as análises estatísticas.

São diversas as dificuldades encontradas por alunos e professores no processo ensino aprendizagem da matemática, e comumente conhecidas. O aluno possui limitações na compreensão dos conteúdos da forma que lhe são apresentados, sendo muitas vezes reprovado nesta disciplina, e quando aprovado, há dificuldade em dar sequência ao aprendizado comprometendo sua qualidade. O ensino da matemática tem sido preocupante, pois é a matéria de maior índice de repetência, levando às vezes ao fracasso escolar.

Nota-se no processo de ensino aprendizagem da matemática em geral, uma carência de significação atribuída aos conteúdos. Dewey (1979, p. 75) assinala que, "aprender matemática significativamente implica em conhecer o conceito a partir de suas relações com outros conceitos, notar como ele funciona".

A matemática tem sido trabalhada de forma bastante empobrecedora, onde fórmulas e regras são mecanicamente aplicadas, bem como exercícios com base em modelos pré- 


\section{Volume 1 - Número 14 - Primeiro Semestre de 2013}

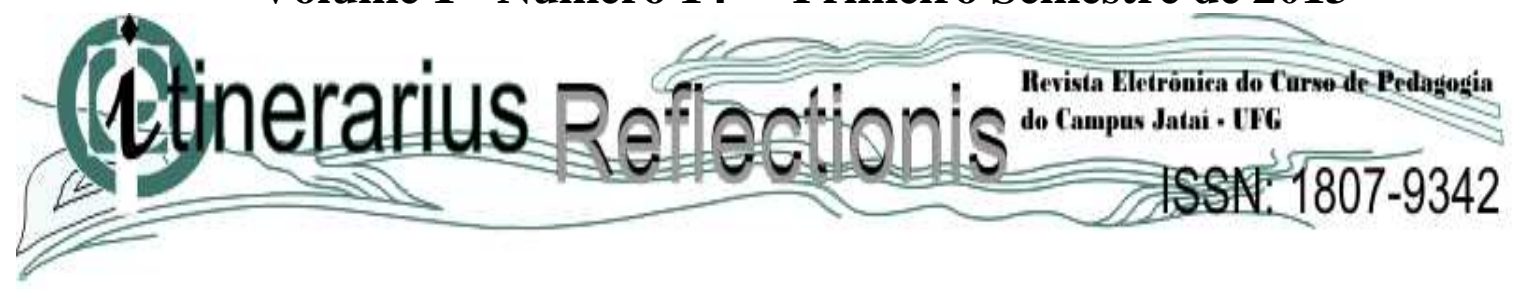

definidos, repetidos e treineiros. Raramente são utilizadas linguagens e metodologias diferenciadas e eficazes para o ensino de matemática.

O conhecimento matemático é apresentado em diversos livros didáticos de forma bastante isolada, sendo tratado como um conhecimento à parte, sem qualquer relação com outras áreas da ciência. D' Ambrósio (2007, p. 31) afirma que: "Do ponto de vista de motivação contextualizada, a matemática que se ensina hoje nas escolas é morta, e poderia ser tratada como um fato histórico".

O professor pode e deve utilizar o livro como material de apoio para o planejamento e orientação de estudos, mas pode também se desprender do comodismo dos livros didáticos, fórmulas e exercícios decorativos e partir em busca de metodologias diferenciadas de ensino.

Segundo D’Ambrósio (2007), “É importante à adoção de uma nova postura educacional, a busca de um novo paradigma de educação que substitua o já desgastado ensino aprendizagem. É necessário que ele se empenhe no mundo que cerca os alunos, na sua realidade aproveitando cada oportunidade a fim de sugerir atividades para que o desenvolvimento do ensino aprendizado da matemática seja efetivo e prazeroso, e que no final de cada aula o educador tenha aplicado a matéria com qualidade e que tenha conseguido ensinar ao aluno de forma clara.".

Incluir metodologias que busquem inovar e contextualizar o ensino na sala de aula no intuito de levar o estudante a construir e compreender a matemática e seus procedimentos que o auxilie na formalização de diferentes conceitos da disciplina parece ser uma alternativa para desmistificar ou "descomplicar" a matemática.

Acreditamos que situações cotidianas articuladas às atividades experimentais no ensino de Matemática possibilitam desenvolver no aluno habilidades e competências, tais como: a identificação, a observação, a classificação e a organização dos diferentes fenômenos envolvidos no assunto.

Os Parâmetros Curriculares Nacionais (PCNs) comentam que ao problematizar situações cotidianas articuladas aos conceitos matemáticos permitem que o aluno, faça interrelações entre os seus vários conceitos e entre os seus diversos modos de representação, 


\section{Volume 1 - Número 14 - Primeiro Semestre de 2013}

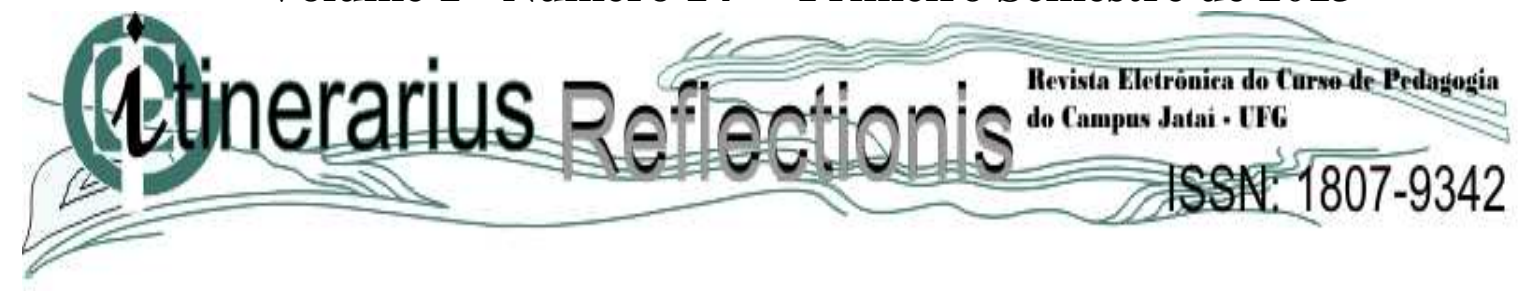

superando obstáculos desde os mais simples até aqueles que significam verdadeiras barreiras epistemológicas no seu desenvolvimento (BRASIL, 1998).

Micotti (1999, p. 162) ressalta sobre a importância do ensino da matemática estar vinculado a situações da vida diária:

O caráter abstrato dos estudos matemáticos surpreende os principiantes nos primeiros contatos com o mundo de ideias e representações, desprovidas das particularidades das coisas materiais. Apesar de a matemática ser utilizada e estar presente na vida diária, exceto para quem já compartilha desse saber, as ideias e os procedimentos matemáticos parecem muito diferentes dos utilizados na experiência prática ou na vida diária.

Nesse processo de formação é preciso considerar as transformações sociais que emergem com o passar do tempo e que por decorrência acarretam em outras demandas no mercado de trabalho. O mundo atual exige outros conteúdos, naturalmente outras metodologias, para que se atinjam os objetivos maiores de criatividade e cidadania plena (D’AMBRÓSIO, 2007).

Alcançar a cidadania significa, também, entender a Matemática como uma ciência dinâmica que se atualiza em conformidade com as transformações sociais extrapolando a visão simplista e cartesiana de que essa ciência se resume a aplicação de fórmulas e resolução de algoritmos. Segundo os documentos oficiais do governo como os PCNs:

[...] a Matemática pode dar sua contribuição à formação do cidadão ao desenvolver metodologias que enfatizem a construção de estratégias, a comprovação e justificativa de resultados, a criatividade, iniciativa pessoal, o trabalho coletivo e a autonomia advinda da confiança na própria capacidade para enfrentar desafios. (...) a compreensão e a tomada de decisões diante de questões políticas e sociais dependem da leitura crítica e interpretação de informações complexas, que incluem dados estatísticos e índices divulgados pelos meios de comunicação, ou seja, para exercer cidadania é necessário saber calcular, medir, raciocinar, argumentar, tratar informações estatisticamente (BRASIL, 1998, p.27)

Existem diversas formas de desencadear os conceitos da Matemática e a prática pedagógica escolhida pelo professor é determinante nesse contexto. É papel de o educador fornecer subsídios para que os estudantes compreendam tanto os conceitos abstratos quanto as manipulações simbólicas, que são consideradas insuficientes na maioria das salas de aula. 


\section{Volume 1 - Número 14 - Primeiro Semestre de 2013}

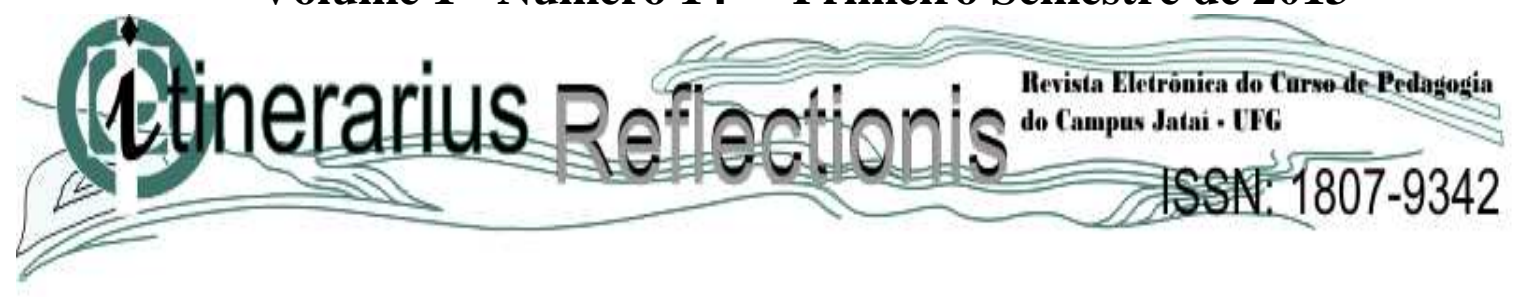

O professor deve ter claro que o planejamento curricular é realmente flexível, que seu empenho através de práticas diárias e concretas, interativas e inter-relacionadas em que os conteúdos trabalhados sejam articulados de modo a facilitar a compreensão e a aprendizagem do aluno.

Nas salas de aulas o público é diferenciado no aspecto socioeducativo e com características e níveis de aprendizagem completamente diferentes, permitindo assim que o professor proponha técnicas e dinâmicas que possibilitem ao aluno uma maior formação de novas estruturas, a partir de orientações básicas, mas fundamentais, na construção, de expectativas futuras que possam contribuir na reversão do atual ensino da matemática, que é acusado com níveis de insucesso e fracasso escolar na disciplina de matemática.

A matemática apresentada atualmente nos currículos oficiais, assim como nos manuais didáticos, apresenta os conteúdos como sendo uma reprodução de resultados sem contextualização, ou melhor, sem significados.

Outros aspectos negativos também permeiam o ensino da matemática e são repassadas pelo fator cultural, como as metodologias de ensino inadequadas onde os professores se fundamentam em transmissão, repetição e memorização de conteúdos matemáticos e aulas sem motivação para a aprendizagem. Assim ainda, o resultado do ensino nas séries iniciais do Ensino Fundamental, tem-se reduzido ao fracasso, ao desestímulo e ao abandono das raízes dessa ciência que ao longo do tempo arquitetou não só a lógica, mas a linguagem, os costumes, os valores, as crenças e os hábitos dos povos.

O conhecimento sobre como as crianças aprendem Matemática e que tipo de matemática pode ser aprendido, nos diferentes estágios de maturação, tem sido validado rapidamente, mas em geral, ignorado na ação e prática pedagógica dos professores. Estudiosos, pesquisadores têm descoberto ou redescoberto, estratégias e proposições para viabilizar a estrutura do ensino de matemática mais compreensível para os alunos nas séries iniciais do Ensino Fundamental, dentre elas destacamos nesse trabalho o uso de materiais concretos, como importante ferramenta pedagógica.

Desde já no século XIX, Pestalozzi, defendia que a educação deveria começar pela percepção de objetos concretos, com a realização de ações concretas e experimentações. 


\section{Volume 1 - Número 14 - Primeiro Semestre de 2013}

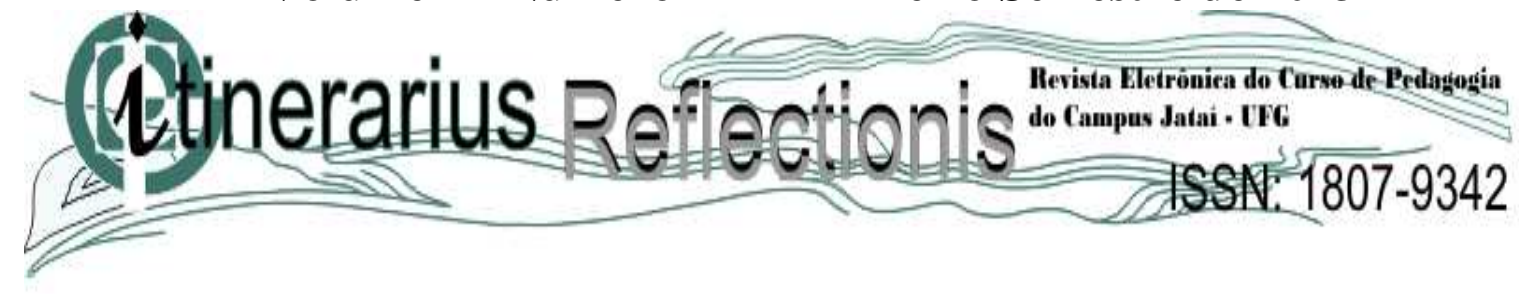

A vida de Pestalozzi foi um exemplo fantástico de amor e devoção à educação, entre fracassos sucessivos e uma persistência gloriosa em sua missão de educador. Escritor de vários livros ele também construiu uma escola em sua casa para compartilhar seu conhecimento com os alunos da região, o mesmo contribuiu para a união entre o material manipulável e a prática pedagógica.

Pestalozzi acreditava que uma educação seria verdadeiramente educativa se proviesse da atividade dos jovens. Fundou um internato onde o currículo adotado dava ênfase às atividades dos alunos tais como canto, desenho, modelagem, material manipulável, excursões ao ar livre, em que as descrições deveriam preceder as definições e o conceito nascia da experiência direta e das operações sobre as coisas.

Já no século XX, Euclides Roxo, em 1929, começava a chamar a atenção dos colegas para esse método. Euclides de Medeiros Guimarães Roxo Aracaju nasceu dia 10 de dezembro de 1890 e faleceu no Rio de Janeiro, em 21 de setembro de 1950. Ele foi professor de matemática e diretor do Colégio Pedro II, propôs à Congregação do Colégio, em 1927, uma mudança radical no ensino da matemática, tendo como ponto principal acabar com a matemática ensinada em partes distintas e separada (aritmética, álgebra e geometria), ensinando-as como uma única matemática. Contribuiu na valorização e divulgação do uso de material manipulável como recurso auxiliar nas aulas de matemática.

Alguns teóricos da psicologia moderna, que tratam dos estudos da aprendizagem e estudiosos do campo da psicopedagogia clínica e institucional tem fornecido elementos em uma analise racional para o uso de materiais concretos no desenvolvimento da criança. Para Piaget (1998), o conhecimento se dá através de um processo de interação. A partir do momento em que o sujeito interage em contato com o objeto, um modifica o outro, assim ocorre à construção do conhecimento pelo sujeito.

Através desta interação o sujeito vai modificando suas estruturas e aprendendo pelos processos de assimilação e acomodação, ou seja, quando o sujeito encontra com algo novo ele inicia o processo de adaptação que inclui estas duas formas: a assimilação e a acomodação.

$\mathrm{Na}$ assimilação o indivíduo utiliza os conhecimentos que já possui, já na acomodação, se estes conhecimentos não forem suficientes, é preciso construir novas 


\section{Volume 1 - Número 14 - Primeiro Semestre de 2013}

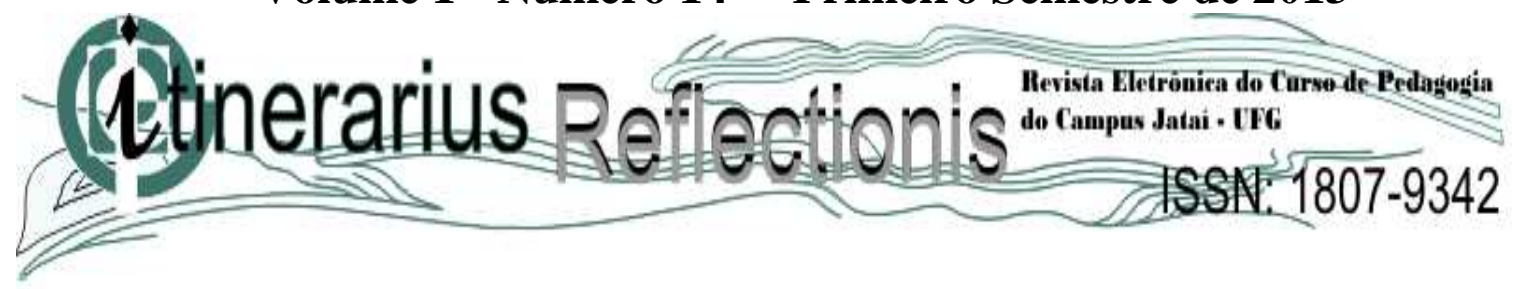

estruturas. Este processo de formação de estruturas envolvendo assimilação e acomodação é contínuo na construção do conhecimento durante a vida do indivíduo.

A principal preocupação de Piaget (1998), tem sido mostrar que o desenvolvimento mental da criança ocorre através da maturação, experiência e auto regulagem, conforme a criança passa por etapas no desenvolvimento da inteligência:

- Sensório-motor: do nascimento até dois anos de idade;

- Pré-operacional: dos dois anos até os sete;

- Operações concretas: dos sete aos onze anos;

- Operações formais: dos onze aos quinze.

As crianças quando entram no período do estagio operatório, necessitam manipular objetos concretos para descobrir os conceitos matemáticos que estão sendo ensinados, já que é possível que a matemática envolva ações efetuadas com objetos manipuláveis.

Piaget (1998) apresenta fortes argumentos para se acreditarem que se deva fornecer sistematicamente, à criança até os onze anos de idade oportunidades para experimentar e descobrir princípios matemáticos e científicos, por si mesma.

A criança deveria começar com a manipulação de objetos físicos e então passar ao trabalho com representação de objetos físicos. No nível semi-concreto o uso de figuras, cartazes, gravuras, tabelas e diagramas, podem fazer a ligação entre as manipulações físicas e os conceitos abstratos.

Piaget (1993), também destaca que o fracasso escolar no ensino de matemática é devido à abordagem e não ao conteúdo e ocorre principalmente por causa da passagem, rápida demais, do concreto para o abstrato. Esses padrões de transição tende atenuar também na transição do aluno das series iniciais para as series finais do Ensino de Fundamental, quando há uma distinção muito grande das metodologias e da práxis pedagógica do professor licenciado em pedagogia e/ou normal superior que ministram aulas de matemática que possibilitam um ensino de matemática com material concreto e por outro lado com os professores licenciados em matemática que já ensinam matemática com abstração. 


\section{Volume 1 - Número 14 - Primeiro Semestre de 2013}

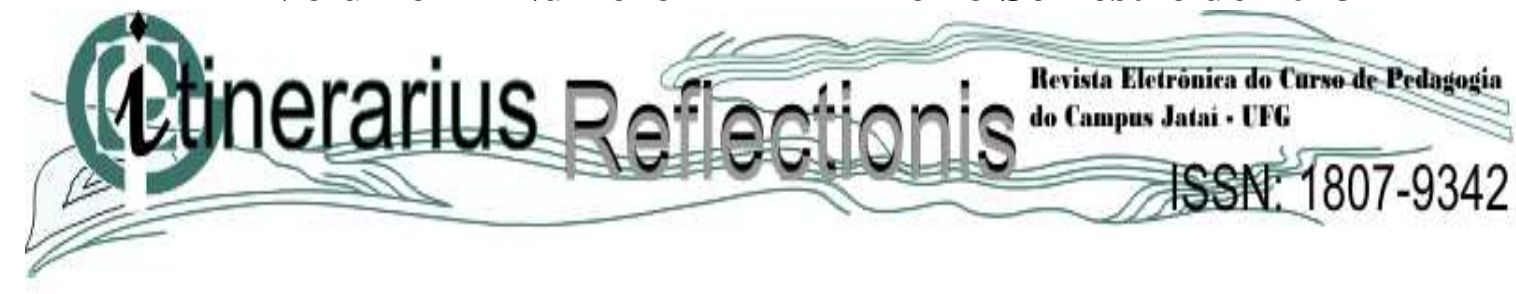

Para Rosa Neto (1992, p. 45), “A aprendizagem deve processar-se do concreto para o abstrato. Toda atividade feita com material pode ser repetida, de diversas formas graficamente. É o primeiro processo de abstração".

Além destes se destacou também: Rosseau (1727-1778) que considerava a educação um processo natural do desenvolvimento da criança, através do jogo, Montessori (1870-1932) e Decroly (1871-1932) inspirados nas ideias de Pestalozzi queriam desenvolver uma didática especial.

Os professores que ministram aulas de matemática nas séries iniciais do Ensino Fundamental, quando entram em uma sala de aula, sabendo que poderá se deparar com dificuldades ao ensinar, enquanto busca atingir êxito e satisfação.

Os materiais manipuláveis ou material concreto é uma proposta viável de metodologia para melhoria no ensino da matemática, pelo qual vem marcando forte presença atualmente.

Segundo Schliemann (1995, p. 178), “O ensino de matemática no Brasil, após ter sido basicamente formal, foi estimulado pela ideia da introdução de "materiais concretos" em sala de aula".

\footnotetext{
A grande maioria dos livros didáticos atuais destinados às séries do ensino fundamental trazem sugestões de uso de materiais concreto. (...) é comum percebermos certa confusão sobre o papel do material concreto na aprendizagem da matemática.
}

As escolhas pedagógicas, a definição de objetivos e conteúdos de ensino e as formas de avaliação estão ligadas às concepções do professor, por isso é necessário refletir sobre a sua prática, identificar as principais características desta ciência e seus métodos de aplicações, conhecer a história de vida dos alunos, sua vivência de aprendizagem, seus conhecimentos sobre o assunto, ter clareza de suas próprias concepções sobre a matemática.

Lorenzato (2006, p. 56) diz que:

O professor deve saber utilizar corretamente os materiais didáticos, pois estes exigem conhecimentos específicos de quem os utiliza. Não se pode deixar que o material se tornasse apenas um brinquedo para o aluno. 


\section{Volume 1 - Número 14 - Primeiro Semestre de 2013}

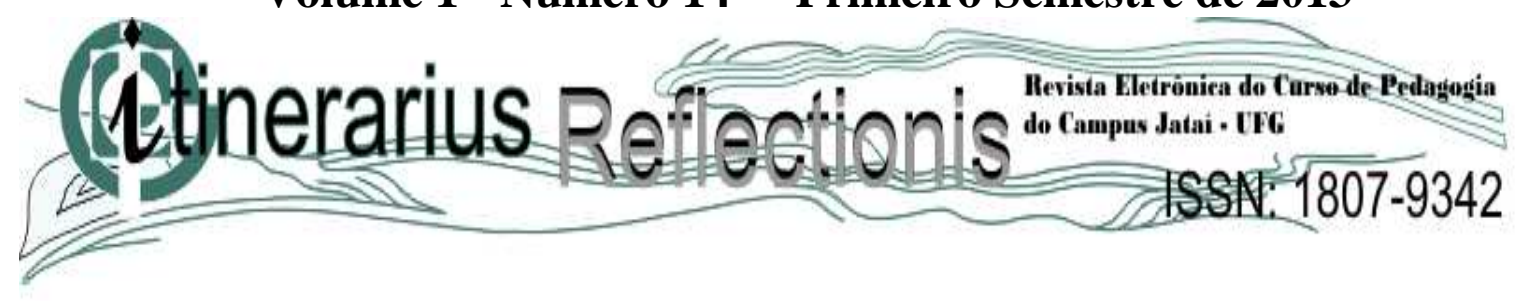

Os Parâmetros Curriculares Nacionais (BRASIL, 1998) também destacam a utilização de materiais concretos pelos professores como um recurso alternativo que pode tornar bastante significativo o processo de ensino-aprendizagem da Matemática. Contudo, Magina e Spinillo (2004, p. 11) destacam que: o material concreto não é o único e nem o mais importante recurso na compreensão
matemática, como usualmente se supõe. Não se deseja dizer com isso que tal recurso
deva ser abolido da sala de aula, mas que seu uso seja analisado de forma crítica,
avaliando-se sua efetiva contribuição para a compreensão matemática.

É preciso refletir sobre os processos e materiais manipuláveis a serem utilizados, pois o mais importante no ensino e aprendizagem da matemática é a atividade mental a ser desenvolvida, ou seja, em cada aplicação deve haver uma sequência didática com objetivos correspondentes, visando estimular a percepção de conceitos abstratos.

É necessário atentar aos professores sobre alguns elementos importantes na utilização de materiais concretos: noções matemáticas se formam na cabeça da criança e não está no próprio material; o material favorece o aprendizado, desde que seja bem utilizado.

É comum em algumas escolas seguirem manuais didáticos com orientações para o uso de material concreto de forma equivocada não levando em conta a aprendizagem e o conhecimento da criança.

Atualmente já existem diversos materiais para manipulação do ensino e aprendizagem da matemática que utilizam propostas mais recentes do sócio-construtivismo. Com isso o professor pode utilizar a forma industrializada ou exercitar a produção pelos alunos.

Freitas (2004) afirma que todos os materiais têm como característica principal o fato de oferecer suporte aos alunos, a partir da manipulação, entender conceitos importantes. A potencialização do uso destes instrumentos depende única e exclusivamente da vontade e da capacidade de criação dos professores.

$\mathrm{Na}$ prática, os alunos devem manusear conhecer o material concreto, antes de quaisquer explicações ou aulas teóricas e do trabalho com lápis e papel. É preciso que os alunos tenham tempo e liberdade para explorar o material, brincar um pouco com ele, balbuciar, familiarizar e fazer descobertas sobre sua organização. 


\section{Volume 1 - Número 14 - Primeiro Semestre de 2013}

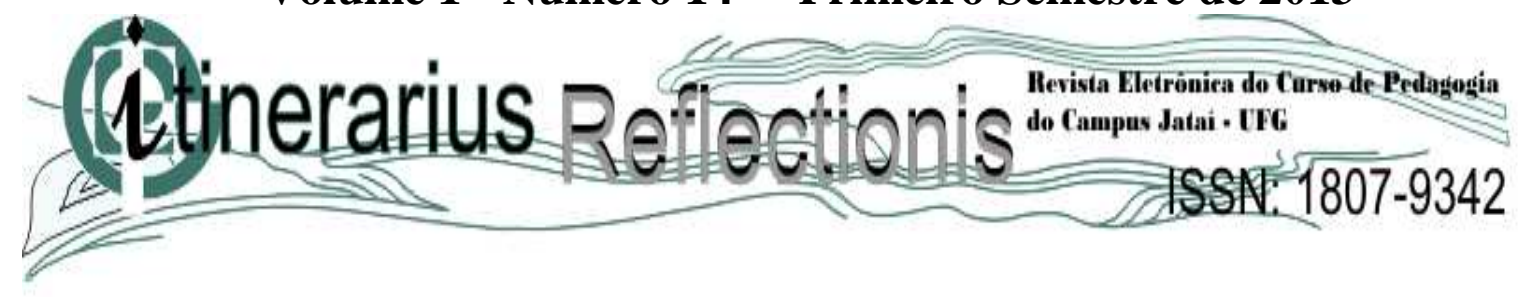

Depois de decorrido algum tempo de trabalho livre, que costumamos chamar de hora lúdica, o professor pode fazer sua intervenção pedagógica, propondo e estimulando os alunos a manifestarem sua opinião e suas diversas expressões. Assim, já serão realizadas ações em que o raciocínio do aluno, pois, é só ele mesmo que pode formar as noções matemáticas.

A partir da observação e manipulação, deve haver um dialogo entre alunos e professor, possibilitando que as relações matemáticas comecem a ser percebidas, enunciadas e os professores aos poucos, devem ir organizando esse conhecimento e a aprendizagem significativa.

A teoria da aprendizagem de Ausubel (1982) propõe que os conhecimentos prévios dos alunos sejam valorizados, para que possam construir estruturas mentais utilizando, como meio, mapas conceituais que permitem descobrir e redescobrir outros conhecimentos, caracterizando, assim, uma aprendizagem prazerosa e eficaz.

A aprendizagem é muito mais significativa à medida que o novo conteúdo é incorporado às estruturas de conhecimento de um aluno e adquire significado para ele a partir da relação com seu conhecimento prévio. Ao contrário, ela se torna mecânica ou repetitiva, uma vez que se produziu menos essa incorporação e atribuição de significado, e o novo conteúdo passa a ser armazenado isoladamente ou por meio de associações arbitrárias na estrutura cognitiva.

É importante destacar que a utilização do material concreto por si só, não garante aprendizagem, é fundamental o papel do professor nesse processo, enquanto mediador da ação e articulador das situações experienciadas no material concreto e os conceitos matemáticos, para uma posterior abstração e sistematização.

Ao utilizarmos o material concreto podemos estar facilitando a alfabetização matemática. Segundo Kamii (1990, p. 44) as "relações são criadas pelas crianças a partir de seu interior e não lhes são ensinadas por outrem. No entanto, o professor tem um papel crucial na criação de um ambiente material e social que encoraje a autonomia e o pensamento".

Freire (1996, p. 24) lembra que "ensinar não é transferir conhecimento, mas criar as possibilidades para a sua produção ou a sua construção." Cabe ao professor criar um ambiente favorável às discussões, levando em conta também os conhecimentos dos alunos, para que 


\section{Volume 1 - Número 14 - Primeiro Semestre de 2013}

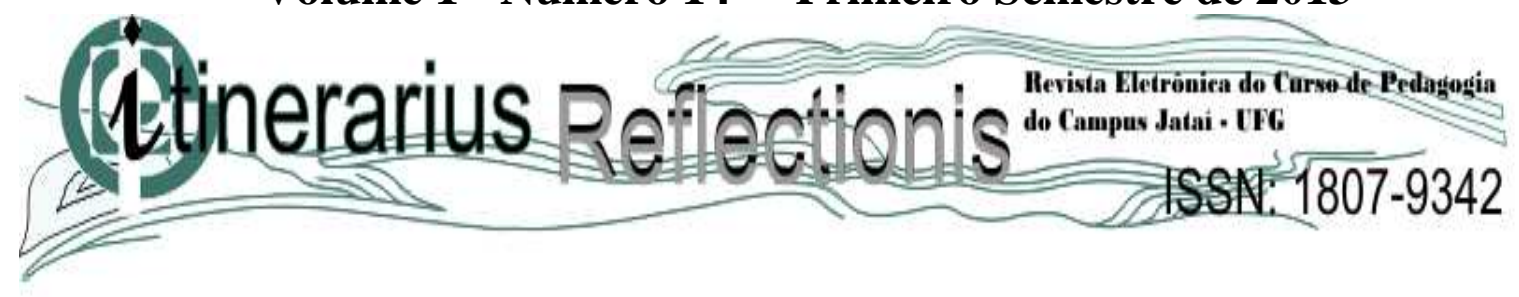

haja trocas de saberes. Porém, para assumir essa postura na prática docente é necessário atentarmos para uma formação continuada de professores que contemple tal atitude.

Essa experiência com materiais concretos permitem as crianças a realizar as contas internamente, raciocinando de forma abstrata e produzindo certo conhecimento matemático. Isso não significa que basta colocar na frente de uma criança diversos objetos de contagem para que ela passe a compreender um determinado conteúdo. O entendimento depende de ações pedagógicas com os materiais concretas propostas pelo professor que auxiliem essa compreensão.

A maioria dos materiais concretos adapta-se a vários conteúdos, objetivos e a turmas de diferentes idades - da Educação Infantil ao Ensino Fundamental e Médio. Eles despertam a curiosidade, estimulam o aluno a fazer questionamentos, a descobrir diferenças e semelhanças, a criar hipóteses e a chegar às próprias soluções, enfim a se aventurar pelo mundo da matemática de maneira leve e divertida.

A atitude adequada do professor, o conhecimento didático e pedagógico em relação ao uso do material concreto no ensino da matemática é de suma importância tanto para os pedagogos que ministram aulas de matemática nas séries iniciais para os professores licenciados em matemática para as series finais e ensino médio deve proceder como um convite à exploração e à descoberta e ao raciocínio, à participação ativa do sujeito, sua atividade auto estruturante, o que supõe a participação pessoal do aluno na aquisição de conhecimentos, de maneira que eles não sejam uma repetição ou cópia de exercícios formulados pelo professor ou pelo livro-texto, mas uma reelaboração pessoal e construtiva.

\section{CONSIDERAÇÕES FINAIS}

Buscamos através de este trabalho analisar a importância do uso de material concreto no ensino de matemática nas séries iniciais do Ensino Fundamental, visto que o manuseio de materiais concretos já é uma atividade que se inicia na Educação Infantil e própria dos alunos podendo se desenvolver de maneira individual ou coletiva. . 


\section{Volume 1 - Número 14 - Primeiro Semestre de 2013}

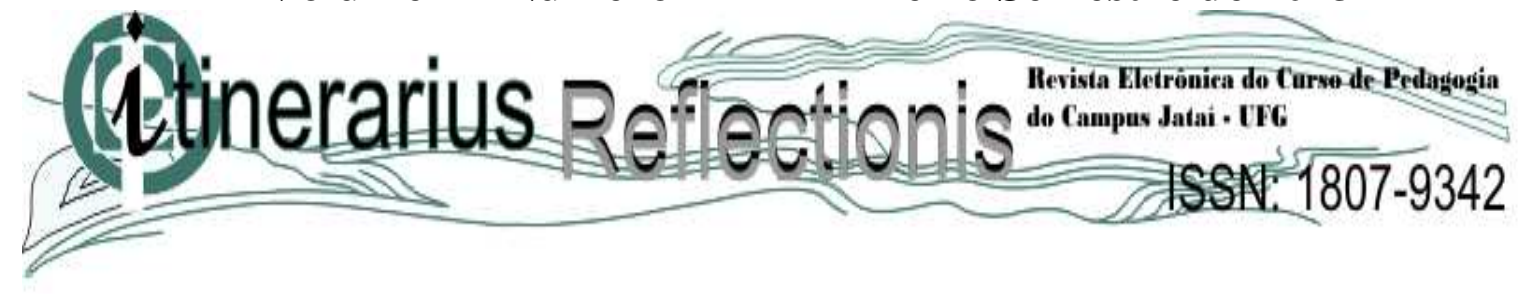

O material concreto desenvolve o raciocínio do aluno, estimula o pensamento lógico matemático e faz com que o educando aprenda sem receber pressão psicológica. Contudo, o educando aprende muito mais facilmente o conteúdo, com prazer e as informações que obtém não esquece tão facilmente.

É importante que o professor conheça a importância da utilização do material concreto de forma adequada e lúdica Consideramos ainda que o material concreto é uma importante ferramenta pedagógica para facilitar a relação professor/aluno/conhecimento no momento em que um saber está sendo construído e que as relações matemáticas não estão no objeto em si, elas podem se formar na cabeça da criança, desde que o material seja bem utilizado no ensino da matemática.

É de acordo com essas considerações que entendemos que os objetivos deste trabalho e de que materiais concretos estruturados, semiestruturados e outras ações poderão ser contemplados no futuro, contribuindo para a melhoria do ensino da Matemática e a desmistificação de que a matemática é abstrata e não faz parte do nosso dia a dia.

\section{REFERÊNCIAS}

AUSUBEL, D. P. A aprendizagem significativa: a teoria de David Ausubel. São Paulo: Moraes, 1982.

BRASIL. Secretaria de Educação Fundamental. Parâmetros curriculares nacionais: matemática / Secretaria de Educação Fundamental. - Brasília: MEC/SEF, 1998.

D'AMBROSIO, U. Educação matemática: Da teoria à prática. $14^{\mathrm{a}}$ ed. Local de publicação: Papirus, 2007.

DEWEY, J. Como Pensamos: como se relaciona o pensamento reflexivo com o processo educativo uma exposição. Tradução de Haydée Camargo Campos, 4. ed. São Paulo: Editora Nacional, 1979

FREIRE, P. Pedagogia da autonomia: saberes necessários à prática educativa. São Paulo: Paz e Terra, 1996. 


\section{Volume 1 - Número 14 - Primeiro Semestre de 2013}

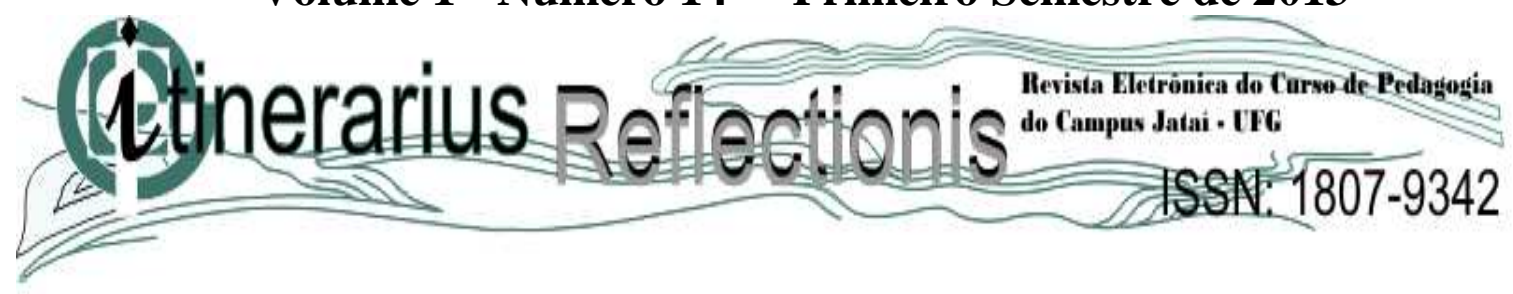

FREITAS, R. C. de O. Um ambiente para operações virtuais com o material dourado / Vitória - ES - 2004. Disponível em: 〈http://ronyfreitas.tripod.com/produção/dissertação.pdf〉 - Acesso em 28 abr 2013.

GRANDO, R. C. O conhecimento matemático e o uso de jogos na sala de aula. Tese doutorado, Faculdade de educação, 2000.

KAMII, C. A criança e o número: implicações educacionais da teoria de Piaget para a atuação com escolares de 4 a 6 anos. Campinas: Papirus, 1990.

LORENZATO, S. Laboratório de Ensino de Matemática na Formação de Professores. Campinas: Autores Associados, 2006. (Coleção Formação de Professores).

MAGINA, S.; SPINILlO, A. G. Alguns 'mitos' sobre a educação matemática e suas consequências para o ensino fundamental. In: Regina Maria Pavanello. (Org.). Matemática nas Séries Iniciais do Ensino Fundamental: A pesquisa e a sala de aula. $1^{a}$ ed. São Paulo: Ed. SBEM, v. 2, p. 7-36, 2004.

MICOTTI, M. C. O. O ensino as propostas pedagógicas. In: BICUDO, Maria Aparecida Viggiani. Pesquisa em educação matemática: concepções e perspectivas. São Paulo: Ed. UNESP, 1999.

PIAGET, J. Seis Estudos de Psicologia. Forense Universitária. Rio de Janeiro, 1993.

A psicologia da criança. Ed. Rio de Janeiro: Bertrand, 1998.

ROSA NETO, E. Didática da matemática. $4^{a}$ ed. São Paulo: Ática, 1992.

SCHLIEMANN, A. L. D.; CARRAHER, D. W.; CARRAHER, T. N. Na vida dez na escola zero. $10^{a}$ ed. São Paulo: Cortez, 1995. 